\title{
Tatjana Minnijahmetova : Az ismeretlen ismerős,
} tanulmányok a baskortosztáni udmurtok vallására

[L'inconnu familier. Études sur la religion des Oudmourtes du Bachkortostan], L'Harmattan kiadó, 2015, 194 p.

\section{Eva Toulouze}

\section{(2) OpenEdition}

\section{Journals}

Édition électronique

URL : https://journals.openedition.org/efo/6982

DOI : $10.4000 /$ efo. 6982

ISSN : 2275-1947

Éditeur

INALCO

Édition imprimée

ISBN : 978-2-343-12463-6

ISSN : 0071-2051

Référence électronique

Eva Toulouze, «Tatjana Minnijahmetova : Az ismeretlen ismerős, tanulmányok a baskortosztáni udmurtok vallására », Études finno-ougriennes [En ligne], 48 | 2017, mis en ligne le 17 juillet 2017, consulté le 08 juillet 2021. URL : http://journals.openedition.org/efo/6982 ; DOI : https://doi.org/ 10.4000/efo.6982

Ce document a été généré automatiquement le 8 juillet 2021

\section{(c) (1) (8)}

Études finno-ougriennes est mis à disposition selon les termes de la Licence Creative Commons Attribution - Pas d'Utilisation Commerciale 4.0 International. 


\section{Tatjana Minnijahmetova : Az ismeretlen ismerős, tanulmányok a baskortosztáni udmurtok vallására}

[L'inconnu familier. Études sur la religion des Oudmourtes du Bachkortostan], L'Harmattan kiadó, 2015, 194 p.

\section{Eva Toulouze}

1 Ce recueil paru en Hongrie, avec la collaboration des anthropologues de Pécs, rassemble des articles que Tatjana Minnijahmetova, une folkloriste oudmourte issue elle-même du Bachkortostan, a publiés au cours des dernières décennies dans des langues différentes - en russe, en anglais, en estonien. Les articles ont été revus et corrigés, adaptés pour éviter l'abondance des répétitions dans la conception de cet ouvrage qui est l'un des rares sur la religion oudmourte de la diaspora orientale dans une langue autre que le russe.

2 Il convient tout d'abord de s'en féliciter. En presque 200 pages, cet ouvrage nous propose un aperçu extensif du champ de la vie spirituelle de la population oudmourte d'outre-Kama. Le fait qu'il existe en hongrois permettra au moins aux finno-ougristes d'avoir accès à ces informations jusqu'ici fort confidentielles hors de Russie. L'énumération des têtes de chapitre permet de juger de la richesse du matériau abordé :

- Des dieux et des esprits ;

- De la culture des sacrifices ;

- De la situation des lieux sacrés sur la base de l'exemple du village de Bajdašy ;

- Du caractère cyclique du temps et de l'espace ;

- De l'orientation : que la maison regarde le soleil !;

- De l'étuve ;

- Du puits ;

- Du cas du chien et du chat jetés dans le puits ;

- Des rituels liés à la naissance ;

- De l'influence des paramètres temporels sur la guérison des maladies ;

- De la mort et des défunts. 

même temps qui peut parler à un lecteur des temps présents. En effet, dans ces régions à dominante musulmane - ce qui a permis aux populations oudmourtes de garder leur culture face à l'intolérance des missionnaires chrétiens dans leurs terres d'origine - les Oudmourtes ont préservé leur religion propre. Celle-ci repose sur un postulat que les grandes religions à dogme et à vérité révélée ont toujours combattu, mais qui nous donne un bel exemple de tolérance religieuse: "Dieu est un, les religions sont différentes. » Autrement dit : les voies qui mènent à lui diffèrent, mais toutes, elles ont droit de cité. Certes, Tatjana Minnijahmetova n'insiste pas sur ce trait fondamental de la religion oudmourte, mais je le rencontre tous les jours au cours de mes travaux de terrain dans cette même région et je trouve que cette religion, présentée comme primitive par les tenants de l'orthodoxie et de l'islam, est porteuse d'un véritable message d'actualité en 2017.

7 Non seulement cette culture mérite d'être connue, mais l'auteure est particulièrement compétente pour nous la faire connaître. Folkloriste reconnue, elle est elle-même porteuse de la culture qu'elle étudie, de sorte que ses textes sont intéressants à deux titres : par le sérieux scientifique dont ils sont porteurs mais également par leur valeur de témoignage.

8 Il n'en reste pas moins que ce livre suscite quelques questions que je voudrais poser dans cette recension, sur la base entre autres de mes propres recherches et de mon expérience de terrain de quelques années au Bachkortostan. Je pense que ce type de dialogue est absolument indispensable dans une saine vie scientifique.

9 Ma première question n'est pas personnelle, elle reflète une perplexité que j'éprouve en permanence face à l'ensemble de la littérature existant en Russie sur les cultures traditionnelles. En fait l'ethnographie russe part d'un postulat: c'est une discipline auxiliaire de l'histoire. Donc son approche est principalement historique et l'œuvre de Tatjana Minnijahmetova ne fait pas exception : ses principales sources sont des sources du XIX ${ }^{e}$ siècle et du début $d u X^{e}$ siècle, ce qui explique que c'est surtout cette époque qui est étudiée dans ses travaux. Cette orientation fait que l'objectif des ethnographes russes - et Tatjana Minniahmetova, comme le prouve cette œuvre, s'inscrit pleinement dans leur tradition - est de reconstruire l'état des sociétés étudiées au début du $\mathrm{XX}^{\mathrm{e}}$ siècle, c'est-à-dire "avant l'arrivée de la modernité », avant l'intervention de changements brutaux et destructeurs pour les sociétés rurales. Le résultat que Tatjana Minnijahmetova nous montre ici est une accumulation de pratiques dont la 
chronologie est incertaine : certaines sont attestées dans les années 1870, d'autres dans la deuxième décennie $\mathrm{du} \mathrm{xx}^{\mathrm{e}}$ siècle, d'autres encore par les terrains de l'auteur. Il nous est souvent dit que tel ou tel rituel se pratique encore aujourd'hui. Comme page 116: «Sur les actes présentés ici, certains sont accomplis par les Oudmourtes jusqu'à aujourd'hui.»

Lesquels? Dans quelles conditions, sous quelles formes? Tout cela reste trop flou à mon goût.

Je vais prendre uniquement deux exemples pour illustrer mon propos. Il est question page 18 de gidmurt ou gidkuz'o, l'esprit protecteur de l'étable qui veille sur les animaux et s'occupe des chevaux. Cette information provient d'une source de 1915. On nous dit que si les animaux meurent, c'est que ce même esprit ne veille plus sur eux et qu'il faut lui faire une offrande et la laisser sur un poteau de l'étable. Là, c'est une information provenant d'une source de 1995. Puis on nous dit que si les gens tombent malades, les Oudmourtes lui faisaient offrande d'un tétras ; si les animaux tombaient malades, ils lui offraient deux brochets. Cette information remonte à 1921. Puis nous apprenons que si les bêtes présentent des plaies et ont l'air malade, on fait offrande d'un emballage contenant de la farine, du gruau et du sel, avec une formule magique. Cette information remonte à 2001. Du coup, on a du mal à comprendre le statut de ces différentes informations les unes par rapport aux autres. Est-ce que ces pratiques ont été, à une certaine date, simultanées? Est-ce que certaines d'entre elles ont cessé d'être pratiquées à un moment donné ? Si nous nous faisons effectivement une idée de ce qui entoure et a entouré le gidmurt, cette énumération pose autant de questions qu'elle en résout. Encore : il nous est dit (p. 20) au présent de l'indicatif, que "quelques années après la mort des parents, on fait un sacrifice en leur honneur : un cheval pour le père, une vache pour la mère ».

12 Or je sais que depuis des décennies les Oudmourtes ne sacrifient plus de chevaux. J'ai même visité (en 2015 et 2016) un cimetière, celui de Votskaja Ošja (voir supra), le dernier où les Oudmourtes procèdent à la cérémonie en question, appelée ici ullon c'öton, mais où le sacrifice offert pour le père comporte désormais deux oies au lieu d'un cheval. La formulation de Tatjana Minnijahmetova se révèle donc inexacte si on prend le présent au pied de la lettre; mais les choses sont plus compliquées : cette formulation reflète un état de choses passé, c'est-à-dire qu'elle devient acceptable si on analyse ce présent comme un présent de narration... C'est évidemment ce qu'il est, car la perspective de notre chercheuse, nous l'avons compris, n'est pas une perspective présente, mais une perspective passée, et donc, forcément, son présent, par défaut, ne peut être qu'une projection dans le passé. Je ne vais pas multiplier les exemples.

13 Pour conclure sur ce point, je dois avouer que je suis gênée par le principe qui consiste à présenter la société oudmourte actuelle comme un état dégradé d'une culture qui avait atteint ses sommets avant 1917. Je préfère considérer chaque état de cette société comme un tout à part entière, en son plein droit, et l'étudier aussi bien dans sa synchronie que dans la continuité historique. Donc, ce qui me manque dans ce livre, c'est la vie des Oudmourtes du Bachkortostan aujourd'hui. C'est d'autant plus dommage qu'une chercheuse issue de ce milieu ne peut qu'être bien outillée pour rendre compte des réalités du début du $\mathrm{xxI}^{\mathrm{e}}$ siècle. Elle pourrait valoriser cette culture présente mieux qu'elle ne le fait. Par exemple à propos de son propre village où sans doute les cérémonies se poursuivent-elles, elle nous dit : 
Il n'y a plus aujourd'hui dans le village de responsable des cérémonies ayant une formation adéquate. Le dernier sacrificateur bien informé sur les questions religieuses et connaissant bien les rites était Garejšin Nadyrsa babaj, qui dans son âge avancé, à la fin des années 1970, est parti s'installer chez ses enfants à Iževsk (p. 45). indépendante de la première. Il s'agit d'une contradiction que je ressens entre les observations de l'auteur de ce livre et mes propres constatations de terrain. En effet, Tatjana Minnijahmetova ne cesse de mettre l'accent sur la sévérité de cette culture construite sur les interdits : énormément de choses sont « rigoureusement interdites ». On a des exemples pages $38,43,67,70,71,72,73,75,81$, etc. Or cela est en contradiction avec ce que je constate dans mes terrains, c'est-à-dire depuis quatre ans. Je n'ai pas noté de sévérité particulière. Bien sûr on peut objecter d'emblée que mon statut d'observatrice extérieure oriente peut-être mes interlocuteurs dans leur manière de s'adresser à moi. Mais mes observations portent également sur l'atmosphère générale qui nous entoure et je n'y note pas de sévérité particulière. Je ne veux pas dire bien sûr qu'il n'y a pas d'interdits dans cette culture. On les rencontre tous les jours: par exemple sur le plan vestimentaire, on ne va pas à une cérémonie habillé n'importe comment - hommes et femmes ont la tête, les bras et les jambes couverts ; les femmes n'ont pas toujours accès à tous les emplacements. En même temps j'ai constaté qu'il y a des infractions à ces règles. Ces infractions ne sont pas accueillies avec indifférence, mais elles ne suscitent pas l'indignation : la réaction n'est pas ce que je qualifierais de sévère. On va dire aux enfants venus en short de rentrer mettre un pantalon à la maison. Par deux fois, notre compagnon ethnographe oudmourte, Ranus Sadikov, a rencontré un problème de cet ordre : en juin 2013, il n'avait pas de couvre-chef, il s'en est excusé et les choses en sont restées là ; de même, en juin 2015, alors qu'il portait une chemise à manches courtes, l'organisatrice de la cérémonie lui a donné une veste pour qu'il ait les bras couverts en entrant dans l'espace sacré et lui a dit que, plus tard, ce ne serait pas trop grave. Ce n'est pas ce que j'appelle une réaction sévère. Dans l'un des groupes religieux du raïon de Tatyšly, l'un des espaces délimités par une palissade n'est pas, en principe, ouvert aux femmes. Mais j'ai vu comment des femmes de ces localités sont entrées dans l'enceinte sans complexes. Certes on leur a dit de sortir, mais sans emphase particulière.

ors comment expliquer ces contradictions? Je pense qu'il faut revenir à la perspective chronologique et à ses conséquences. Les constatations que je viens d'exposer reflètent mon expérience entre 2013 et maintenant. Nous l'avons déjà vu, la perspective de Tatjana Minnijahmetova est tournée vers le passé. Sans doute sur ce point aussi y a-t-il eu des modifications dans les attentes et dans les comportements. Il est possible également que l'auteur se souvienne des mises en garde parentales au cours de son éducation, qui ont pu être particulièrement sévères. Aujourd'hui tous sont conscients que le lavage de cerveau antireligieux auquel personne n'a échappé a conduit, d'une part, à une ignorance considérable d'éléments de la culture qui allaient 
de soi auparavant et, d'autre part, à une profonde absence de sensibilité envers les interdits d'origine religieuse.

Un passage en même temps intéressant et amusant est le chapitre sur l'histoire du chien et du chat jetés dans le puits ${ }^{1}$. Là, nous avons un cas sorti de la vie même du village au début du $\mathrm{XxI}^{\mathrm{e}}$ siècle avec sa dimension de mystère, de malveillance et de solidarité. Je suis surprise cependant de la manière dont Tatjana Minnijahmetova introduit cet excellent chapitre :

La méthode que j'ai utilisée dans cette recherche, avec tout le respect et le dévouement que j'éprouve pour les porteurs de la culture, peut sans doute être qualifiée de « méthode non scientifique » ou encore d'« approche non scientifique » puisque j'ai fondé ma recherche avant tout sur leurs commentaires, explications et interprétations (p. 108).

C'est-à-dire que pour Tatjana Minnijahmetova la seule approche scientifique est forcément une approche "étique ", distancée, effectuée du point de vue de catégories universelles. Je me permets de polémiquer avec elle et de prétendre que l'approche émique que son étude représente est, pour ce type de domaines, l'approche scientifique par excellence et qu'elle n'a pas à s'en excuser.

Sur certains points, j'aurais préféré que l'auteure utilise des notions plus neutres, moins porteuses de connotations négatives. Ainsi, quand elle écrit page 132: "on utilise non seulement des méthodes de soins rationnelles, mais aussi irrationnelles ", cela semble porter un jugement de valeur sur lesdites méthodes qui, à mon sens, n'a pas sa place dans ce type d'étude.

Ces deux derniers commentaires renvoient à une attitude mentale implicite qui m'attriste plus qu'elle ne me scandalise: la chercheuse, issue en l'occurrence de la communauté qu'elle étudie, semble devoir donner des gages aux porteurs d'une vision positiviste de la recherche, incontestablement dominante en Russie (et en France), et s'excuser de rendre compte d'un univers mental différent, qui laisse une place à des phénomènes et à des pratiques inexplicables dans une approche purement positiviste. Quand on étudie une vision du monde qui diffère de celle - urbaine, scientiste dominant les milieux académiques, il est de notre devoir de la pénétrer et de la présenter de l'intérieur. Nous n'avons pas à nous en excuser, pour peu que nous respections la culture que nous étudions. La condescendance n'y a pas sa place. Je pense toucher ici à un point d'autant plus sensible pour un chercheur autochtone que cette personne, quand elle est dans son milieu d'origine, ne manque pas de partager la vision de son entourage. Elle se sent donc tiraillée entre une vision qui relève organiquement de sa personne et les attentes présumées du milieu dans lequel elle est intégrée. Or ces attentes ne sont que présumées, façonnées par les attitudes souvent envahissantes de certains chercheurs; dans les milieux internationaux des anthropologues, des folkloristes et des ethnologues, ces « attentes » ne sont pas partagées et l'on attend du chercheur un respect fondamental pour les approches émiques. Je sais pertinemment que Tatjana Minniahmetova vit profondément ce respect. Et je suis triste de voir qu'elle se sent obligée parfois (heureusement pas tout le temps) de montrer patte blanche.

21 Une dernière observation avant de conclure. J'ai été un peu troublée par le dernier chapitre dont j'attendais quelque chose de plus méthodologique sur les travaux de terrain que ce que le livre nous propose, une collection d'interdits. Notamment dans la note introductive, Tatjana Minniahmetova rend hommage à ses « maîtres » en matière de travaux de terrain - Valej Kel'makov, Vladimir Vladykin, Ülo Valk - c'est-à-dire aux 
professeurs avec qui elle a fait du terrain. N'ayant pas eu de maîtres en cette matière j'ai commencé toute seule et j'ai continué avec des collègues - j'aurais été intéressée non seulement par l'expression de la gratitude, mais aussi par les causes précises de cette gratitude. Je connais suffisamment les trois professeurs mentionnés pour savoir qu'ils font certainement du terrain de manières très différentes. Ce que chacun a su apporter à Tatjana Minniahmetova aurait pu être édifiant aussi pour son lecteur (et aurait beaucoup fait pour que la reconnaissance qu'elle exprime apparaisse moins formelle).

En tout cas, le livre est là, et nous n'avons pas tant de matériaux à nous mettre sous la dent pour nous permettre de trop faire la fine bouche. J'ai fait les commentaires cidessus car sa lecture m'a incitée à entrer en dialogue avec son auteur. Je suis bien consciente qu'une partie des aspects de ce travail que je critique sont le résultat d'une tradition dans laquelle, justement, je ne m'inscris pas. Mais la diversité des approches en tant que telle ne peut être que souhaitable dans la découverte, aussi riche que possible, des diverses cultures étudiées. Donc réjouissons-nous que ce livre existe et espérons qu'une traduction en sera bientôt accessible dans une langue de plus grande diffusion que le hongrois.

\section{NOTES}

1. On pourra trouver une version anglaise de ce texte avec le lien suivant: https:// www.academia.edu/27371408/

Tatiana_Minniiakhmetova_Tartu_The_Case_of_A_Cat_and_A_Dog_in_a_Well_Motifs_Folk_Inquiry_and_Metafolkloristic_Interpretatio campaign=upload_email [consulté le 28.03.2017].

\section{INDEX}

Index géographique : Bajdašy, Bachkortostan, France, Hongrie, Pécs, Russie, Perm' (kraj'),

Votskaja Ošja, Tatyšly (raïon)

Thèmes : ethnographie, études religieuses

nomsmotscles Oudmourtes d'outre-Kama

motscleset kultuuritraditsioonid, maailmavaade, usupraktilka

Keywords : cultural traditions, religious practice, worldview

motsclesru РЕЛИГИОЗНАЯ ПРАКТИКА, КУЛЬТУРНЫЕ ТРАДИЦИИ, МИРОВОЗЗРЕНИЕ

disciplines anglais, estonien, hongrois, russe

Mots-clés : pratiques religieuses, traditions culturelles, vision du monde

Index chronologique : XXe siècle 